\title{
The relationship of competition and financial commitment revisited: A fuzzy set qualitative comparative analysis in European newspaper markets
}

\author{
Russi, Loris ; Siegert, Gabriele ; Gerth, Matthias ; Krebs, Isabelle
}

\begin{abstract}
Research generally supported a positive effect of competition intensity on financial commitment into news production within U.S. markets. The authors test this assumption across European newspaper markets by applying fuzzy set qualitative comparative analysis. Although oligopolistic too, European newspaper markets reveal a somewhat different pattern. The market condition "high number of competitors" in combination with "high competition intensity" is a sufficient condition for financial commitment across the different markets in this study.
\end{abstract}

DOI: https://doi.org/10.1080/08997764.2014.903958

Posted at the Zurich Open Repository and Archive, University of Zurich

ZORA URL: https://doi.org/10.5167/uzh-95974

Journal Article

Accepted Version

Originally published at:

Russi, Loris; Siegert, Gabriele; Gerth, Matthias; Krebs, Isabelle (2014). The relationship of competition and financial commitment revisited: A fuzzy set qualitative comparative analysis in European newspaper markets. Journal of Media Economics, 27(2):60-78.

DOI: https://doi.org/10.1080/08997764.2014.903958 
The relationship of competition and financial commitment revisited

A fuzzy set Qualitative Comparative Analysis in European newspaper markets

Loris Russi, Gabriele Siegert, Matthias A. Gerth \& Isabelle Krebs 


\section{Introduction}

Research on media consolidation and competition is mainly concerned with the effects on media performance. Our paper revisits the relationship of competition and financial commitment as the conduct of media organizations. The financial commitment approach (Lacy, 1992) suggests a positive relationship between competition intensity and the amount of resources allocated to news production. However, research is almost entirely dominated by application to U.S. markets in the 1980s and 1990s. Theory and research are bound to certain contexts. We investigate whether the traditional financial commitment hypothesis holds true within European contexts today. We focus on the first step of the model: the effect of competition on the financial commitment of media organisations in a given market. The relationship between competition and financial commitment is analysed across six European countries introducing fuzzy set Qualitative Comparative Analysis to media economics. Thus, there will be a special section on this new method outlining its basic principles and differences to more common methods.

\section{The effects of competition on financial commitment}

The concept of financial commitment refers to a certain type of conduct of media organisations. The term was originally introduced by Litman and Bridges (1986). In an attempt to evaluate media ownership research in the U.S. they found that there is "one common thread running through most of the studies which centers around the concept of newspaper performance as the financial commitment of newspapers to providing their editorial product. This concept of performance is not an evaluation per se of the product itself but rather of the resources put forth by a newspaper to produce and deliver such a quality product" (Litman \& Bridges, 1986, p. 10). Following the structure-conduct-performance (SCP) paradigm, the concept of financial commitment as the investment in news production refers to the conduct rather than to the performance dimension. The proximity of the financial 
commitment approach to concepts of industrial organisation theory becomes evident when we take a look at the four step model of effects posited by Lacy (1992). The first step directly links media competition to the conduct of media organizations. Increasing intensity of competition results in an increased financial commitment measured as the resources allocated into the news production. This increase in financial commitment in turn increases the quality of the produced content and therefore audience utility. Finally, this results in higher performance in terms of circulation and advertising revenue. The model posits a positive causal relationship between competition, financial commitment and performance in terms of quality and profit.

Stephen Lacy and others (Lacy, 1992; Lacy, Atwater, \& Qin, 1989; Lacy, Fico, \& Simon, 1989) refined the concept of financial commitment. They argue that the pitfalls of earlier studies on competition's effect on performance are inconsistencies in the measurement of the different concepts (Lacy et al., 1989, p. 3). Instead of using common measures of concentration such as the HHI or simply the number of competitors, these scholars suggest that an index of competition intensity should be applied. The competition intensity index proposed (Lacy et al., 1989, p. 7) reflects the idea that a media organisation tends to react to the closest competitor rather than to the overall market. Therefore, competition intensity is defined and measured as the proximity of competitors in terms of market shares. To a certain degree this concept matches with what economists call rivalry as the behavioural component of competition (McNulty, 1968). In addition, the measurement of the concept of financial commitment is refined. Instead of using an absolute count of the resources allocated to the news, production ratios reflecting an input-output relation should be applied, e.g. the relation between staff and amount of news produced (Lacy et al., 1989, p. 7). The input-output relation reflected in such ratios controls for the size of firms and further allows for comparing results across different markets. 
In general, research has supported the causal and linear effects of competition on financial commitment and performance not only in the case of newspapers but also for TV and radio. In particular, competition intensity was found to increase financial commitment to news production measured as larger newsholes, higher number of wire services, lower workloads per reporter, amount of money spent on local news or more newsroom employees (Busterna, 1980; Lacy et al., 1989; Lacy \& Blanchard, 2003; Lacy \& Riffe, 1994; Litman \& Bridges, 1986; Powers, 1993). Research almost entirely focused on narrow U.S. markets (Lacy \& Simon, 1993). In addition the concept has a temporal constraint since research was mainly conducted between the late 1980s and late 1990s. As such, research as well as theory on financial commitment is bound to certain contexts.

Lacy and Riffe (1994) argue that financial commitment is not a mere function of competition intensity, but also of the profit of and resources available to media firms. They state that "as the number of firms increases in a market, excess profit above normal profit will decline" (Lacy \& Riffe, 1994, p. 588). Lacy and Blanchard (2003) later found evidence that supports this argument. An increase in competition results in a decline in the share of resources available per competitor (Picard, 2002). The financial commitment of media firms is conditioned by the availability of resources (St. Cyr, Lacy, \& Guzman-Ortega, 2005). Already in an early study market size was introduced as a control variable because it may affect managerial decisions on financial commitment (Lacy et al., 1989). Directly related to the resource availability is another boundary of the financial commitment that was already mentioned before. The model is mainly applied to oligopolistic markets or even duopolies within the same city, although there is research that supports the basic assumptions for intercity competition (Lacy, 1988) and large newspapers (Cho, Thorson, \& Lacy, 2004; Lacy et al., 1989; St. Cyr et al., 2005). If we take a look at research on the effects of competition beyond the financial commitment approach there is evidence that with the number of competitors increasing in a market and, thus, resources of the competitors becoming limited 
differentiation strategy and higher investment into content production are increasingly substituted by cost centred strategies (Hollifield, 2006; van der Wurff \& van Cuilenburg, 2001). Simple mathematics illustrate that an increase in the numbers of firms in a given market reduces a firm's share of resources - everything else being equal. Stephen Lacy states that the financial commitment approach may be bound to non-normal profits found in oligopolies, and thus, "[a]n important theoretical issue for future study is whether the financial commitment approach is applicable to media markets that contain large numbers of firms" (Lacy, 1992, p. 14).

It is here, where the aim of this paper comes into play. Research and theory on effects of competition show evidence that an increase of financial commitment might only go as far as resources within oligopolies permit (van Cuilenburg, 1999). A prime example is the work of C. Ann Hollifield and other scholars (Becker, Hollifield, Jacobsson, Jacobsson, \& Vlad, 2009; Hollifield, 2006). Upon a thorough review of the research on financial commitment and other related literature on competition effects they make a case for a curvilinear relationship between competition and performance. The key argument is that an increase in competition for resources does not increase performance infinitely. At a certain threshold, an increase in competition results in a decrease in performance. Although referring to markets that are characterized by hypercompetition due to technological development and, as such, the emergence of new substitutes available to the consumers the underlying logic of the model stems from the research reviewed as well as economic and managerial theory (Hollifield, 2006). The implication of these theoretical remarks is that the relationship between competition and financial commitment may not be entirely linear and positive when applied to European markets today. Possible constraints of the applicability of the financial commitment model to contexts outside the U.S. and markets that are not narrow oligopolies have to be taken into account. 
There is evidence that the basic assumption of the financial commitment is applicable to Japanese markets (Cho, 2000). In addition, the basic argument of the financial commitment approach is a common economic notion. Product differentiation and quality improvement are a way for media firms to prevent unbridled competition for customers (Lacy, 1992; Tirole, 1988; van der Wurff \& van Cuilenburg, 2001). It is, thus, the question whether the assumption of the first step of financial commitment approach holds true in European newspaper markets that are for the most part oligopolies too and market conditions are similar (Hollifield, 2006, p. 60). However, European press systems differ from the U.S., and we know from comparative research that the context influences the markets and the behaviour within the same markets (Picard \& Russi, 2012).

Taken these specifications of possible boundaries of the financial commitment approach it is the aim of the paper to investigate whether the traditional financial commitment assumption of competition intensity effecting financial commitment to news production positively holds true when applied to different contexts in time and space. In line with the set theoretic principle of causality in QCA we formulate the following hypotheses:

H1: High competition intensity in a market with few competitors is a sufficient condition of financial commitment to news production.

$\mathrm{H} 2$ : High competition intensity in combination with high profits in a market with few competitors is a sufficient condition of financial commitment to news production.

Method

\section{Context}

Our study is part of a superior research project. ${ }^{1}$ As such, the data stemmed from a coordinated research effort across six European countries: Denmark, Germany, France, Italy,

\footnotetext{
${ }^{1}$ With regard to the anonymous review the project remains untitled for the time being.
} 
Switzerland, and the UK. The actual sampling process followed the typology of Hallin and Mancini (2004). With regard to the comparative aim of this paper the typology itself is decisive because there are different types of media systems examined. The assumptions of the financial commitment approach are generally supported by research in the U.S. We test the hypotheses across different systems outside the boundaries of traditional research (Kohn, 1987). Against the better part of cross-national research (Livingstone, 2003; Picard \& Russi, 2012) the unit of analysis in this paper is not the nation itself but the market. In order to sample similar markets across the countries we relied on national newspapers and regional dailies within the following metropolitan areas: Berlin, Copenhagen, London, Paris, Rome, and Zurich. On the conduct level, the units of analysis are newspapers. A multi-method approach was established. Desk research on secondary data sources, interviews with media professionals (editors-in-chief and senior managers), and a representative audience survey were conducted.

\section{Sample}

The media outlets are systematically selected within the predefined markets and consist of the leading newspapers measured as total circulation and readership. We argue that the concept of competition intensity suits best in European markets when applied to the most important newspapers because of the need for differentiation from their direct rivals. Only paid and free daily newspapers were included. The markets were then defined based on the audience survey. The financial commitment of media firms aims at competitive advantages through differentiating content. As such, the audience perspective needs to be accounted for (St. Cyr et al., 2005). In terms of participants' sex, age, and residence the samples are representative. Each panel was separately designed at the metropolitan and national level in 
every country. ${ }^{2}$ The method itself was an online-questionnaire. The potential readers were asked which newspapers they read at least once a week presenting a list of the sampled newspapers. Additionally, an item referring to 'other newspapers' and a respective string variable were included. As such, readership for every potential newspaper is measured on the national and regional level. In general, our samples of newspapers drawn on the highest circulation and readership were matched in terms of frequency of usage by the respondents in the survey. In two markets the usage questions led us to add further newspapers to the interviews with media representatives: 'Il Messaggero' in Italy and 'Information' in Denmark. Markets were then further segmented along supply-side characteristics such as free vs. paid dailies and geographic levels leading to the resulting regional and national markets examined. The integration of the supply-side is in line with the principle and measurement of competition intensity acting on the assumption that managers' decisions depend on the behaviour of direct competitors.

Standardized telephone-interviews with media representatives in their respective language (interviews in Denmark were conducted in English) were conducted. Respondents were asked to fill in an online questionnaire while accompanied on the telephone. This allowed us to raise the commitment of the high-level representatives of media companies. A total amount of 28 newspapers constitute the sample. The response was acceptable in Switzerland, Denmark, and to some extent in France and Italy. In Germany a total of N=4 newspaper resulted, but we had to exclude B.Z. because of incomplete reply (table 1). Overall, the response rate was still low, even though media representatives were contacted several times by e-mail and phone. The biggest problem was not the scheduling of the interviews but the availability of the high-ranking representatives at the time and date of the

${ }^{2}$ Berlin ( $\left.\mathrm{N}=741\right)$, Copenhagen ( $\left.\mathrm{N}=749\right)$, London ( $=740$ ), Paris ( $\left.\mathrm{N}=741\right)$, Rome (N=738), and Zurich (N=748). Germany ( $\mathrm{N}=1482)$, Denmark ( $\mathrm{N}=1489)$, UK ( $\mathrm{N}=1494)$, France ( $\mathrm{N}=1495)$, Italy $(\mathrm{N}=1459)$, and Switzerland (N=1523). 
actual interview. The response was especially low in the UK $(\mathrm{N}=1)$ and we would not further evaluate UK-data in our analysis. The overall pattern is partly explained by the fact that we interviewed CEOs (or deputies) and editors-in-chief (or deputies) and were not willing to compromise our sample of representatives in terms of conceptual and methodological equivalence. Respondents needed to have comparable roles in their companies and an overview of the media outlet as a whole.

\section{Method}

To test the traditional assumption of the financial commitment approach we apply fuzzy set Qualitative Comparative Analysis (fsQCA) (Ragin, 1987, Ragin, 2000, Ragin, 2008a). In the following we will shortly outline the principles of QCA and its advantages over traditional analytic techniques such as regression analysis for the study at hand. A general discussion as well as empirical comparisons of QCA and a variety of other methods can be found in: Berg-Schlosser \& Cronqvist, 2005; Goertz, 2003; Katz, Vom Hau, \& Mahoney, 2005; Luoma, 2006; Ragin, 2008a, Ragin, 2006b; Rihoux, 2006. Our data is limited with regard to correlation based methods because the number of observations is very low. This limitation may reveal problems with the estimation of model parameters and inferential statistics. It is even more problematic because testing the traditional financial commitment assumption needs to account for the boundary conditions outlined above. The setting would require the estimation of multivariate regression models and interaction effects because ordinary regression analysis could not reveal a combinatorial influence but solely the net effects of the independent variables on the dependent variable. Thus, the small number of observations becomes an almost insurmountable problem for the application of common methods with the setting of the present study.

In order to circumvent these methodological problems we apply fsQCA. First and foremost, QCA renders reliable results even within small to medium-sized samples (Katz, 
Vom Hau, \& Mahoney, 2005, pp. 567-569; Rihoux, 2006). Second, QCA allows testing for multiple causes at the same time without issues of multi colinearity (Rihoux, 2006). It is a key characteristic of QCA that it does not strictly aim at unravelling the net effect of single variables but at combinations of conditions that are sufficient or necessary for the outcome. These advantages derive directly from the basic principles of QCA (Goertz, 2003; Ragin, 2006b).

The key to the understanding of QCA is that cases should be viewed as combinations of causal conditions (independent variables, X) and outcome (dependent variable, Y) (Ragin, 2006b, p. 18). QCA is about studying cases as configurations of conditions. Thus, combinations of causal conditions are already part of the basic principle of QCA. It is of primary interest whether and which of these combinations of conditions are present at the same time the outcome is present. The set theoretic bases of QCA allows the researcher to identify necessary and sufficient (combinations of) conditions for a certain outcome. Speaking in general terms, $\mathrm{X}$ is sufficient for $\mathrm{Y}$, if the latter is present every time $\mathrm{X}$ is present. Speaking in set theoretical terms, $\mathrm{X}$ is a subset of $\mathrm{Y}(\mathrm{X} \rightarrow \mathrm{Y})$ indicates sufficiency. Contrary, a condition or combination of conditions is necessary if $\mathrm{Y}$ is a subset of $\mathrm{X}(\mathrm{X} \leftarrow \mathrm{Y})$. In short, the configurational principle of QCA allows the researcher to identify combinations of conditions that are causally relevant for an outcome based on the set relations of necessity and/or sufficiency.

In order to assign cases to configurations of conditions these cases must be characterized as members or non-members of every set, i.e. the conditions and the outcome. While crisp sets (cs) are limited to the binary code of full membership (1) vs. full nonmembership (0), in fsQCA variables are calibrated to a graduation of 'full non-membership' to 'full membership' (Ragin, 2000). The respective score indicates the degree of membership in a set, e.g. the set or condition of structurally high competition (NR, table 2). "[F]uzzy sets combine qualitative and quantitative assessment: 1 and 0 are qualitative assignments ('fully 
in' and 'fully out', respectively); values between 0 and 1 indicate partial membership. The 0.5 score is also qualitatively anchored, for it indicates the point of maximum ambiguity (fuzziness) in the assessment of whether a case is more 'in' or 'out' of a set" (Ragin, 2005, pp. 2-3). The process of assigning membership values is called calibration. The researcher defines the three qualitative anchors as 'full membership', 'full non-membership', and the 0.5 point of maximum ambiguity based on theoretical, empirical or substantive knowledge. The original values (e.g. the number of competitors) are transformed along these anchors into fuzzy memberships (for the mathematical procedure, Ragin, 2007). The quantitative or relative differences remain true in fuzzy sets. In sum, fuzzy sets may be seen as continuous variables that are purposefully calibrated to indicate the degree of membership in a predefined set (Ragin, 2005).

Once the basic principles of QCA are understood the technical procedure of the analysis is relatively straightforward. In a so called truth table all logically possible configurations of the causal conditions are listed and cases are assigned according to their membership in the respective conditions. It is the goal of QCA to derive "a logical statement describing the different combinations of conditions linked to an outcome" (Ragin, 2006b, p. 19) by using Fuzzy Algebra. Since a truth table consists of all logically possible configurations of conditions, usually there are configurations not represented by cases. These rows are called remainders (Ragin, 1987). The handling of such remainders (counterfactual analysis, Ragin, 1987, Ragin, 2008a) is crucial, because there is no empirical way of telling whether such configurations of conditions lead to the outcome or not. There are three kinds of counterfactual analysis (Ragin, 2008a, pp. 155-175) that lead to different solutions. We rely exclusively on 'intermediate solutions' where the remainders are explicitly specified, based on theoretical or empirical knowledge (Ragin, 2008a, pp. 155-175).

Two quality criteria are important to understand the analysis with fsQCA and evaluate the set relation under study: consistency and coverage. Fuzzy set theory enables us to test the 
subsethood of X indicating sufficiency via simple arithmetic (Goertz, 2006; Ragin, 2000, Ragin, 2008a). If the membership score of a case in $\mathrm{X}$ is equal or less to the membership in $\mathrm{Y}$, than the criteria of fuzzy subsethood are met. The consistency criterion measures how consistent a condition $\mathrm{X}$ for a certain outcome $\mathrm{Y}$ is with the logic of sufficiency in terms of fuzzy set theory by indicating the proportion of fuzzy memberships meeting the set relation $\mathrm{X} \leq \mathrm{Y}$. One could argue that it is similar to a regression coefficient indicating the strength of the set relation. Coverage on the other hand is similar to the criteria of 'variance explained' (Cooper \& Glaesser, 2011; Rihoux, 2006). It reports the share of the set of the outcome 'covered' by the condition. By taking coverage into account the empirical relevance of a solution can be addressed. Both quality criteria are descriptive like their presumed counterparts in regression analysis.

\section{Measures}

Competition intensity and the number of competitors were measured on the basis of the defined markets. Competition intensity is measured as the inverted distance between a firm's market share and the market share of the leading competitor in the same market (Lacy, 1992). The calculation of the market shares is based on readership per newspaper within the markets. In contrast to the calculation of the market shares based on secondary data relying on the audience survey allowed us for approximating the market shares at the same time the interviews with the media representatives took place. Since the audience sample is representative readership patterns and the market definition are adequate.

Media managers and senior editors were asked about the editorial budget in 2010 and the number of full-time journalists working in the newsroom. These measures of financial commitment form the outcomes (Chen, Thorson, \& Lacy, 2005; Lacy \& Blanchard, 2003). In order to compare the results across different markets and in accordance to the literature on financial commitment these variables were weighted by output of the firms, e.g. staffing ratio 
indicates the number of journalists per 1.000 circulations (see table 2). In addition, media professionals were asked to indicate the past level of profit (2009) on a 5-point scale with profit margin ranges measured as $<0 \%, 0-5 \%, 5-10 \%, 10-15 \%$ and $>15 \%$ (Lacy \& Blanchard, 2003). As posited in $\mathrm{H} 2$ the level of past profit is included as a causal condition because it indicates the internal return of resources. In addition, two context variables are introduced that account for the difference in press systems in terms of availability of resources (Hallin \& Mancini, 2004; Humphreys, 2012) and the development of ad expenditures of the past three years. Both measures rely on the share of ad expenditures into press within the media system.

\section{Calibration of variables into fuzzy sets}

Calibration refers to the assignment of fuzzy memberships to sets under examination (Ragin, 2008a). Calibration uses external criteria as the anchor points and not data-inherent criteria such as the mean or standard deviation. It is of central concern that the definition and information are openly documented. In the following we rely on the direct method (Ragin, 2008a, pp. 89-94). First, we need to specify the target set of each concept. Second, the three benchmarks referring to the qualitative anchor points are defined. When this definition is in operation, the initial values (e.g. the number of competitors) are transformed into fuzzy memberships. The transformation procedure is implemented within the software fsQCA 2.0 (see Ragin, 2008b). In table 1 all the information regarding the calibration is depicted.

\section{$\ll<<$ Place table 1 about here $>>>>$}

The anchor points regarding the set structurally high competition as measured by the number of competitors (NR) are defined accordingly. Van der Wurff and van Cuilenburg (2001, p. 222) set the threshold between moderate and high competition for TV markets at six channels. European press markets are mostly narrow oligopolies (Sánchez-Tabernero \& 
Carvajal, 2002). The two thresholds for assigning full membership and full non-membership must be set at the point where there is arguably no doubt whether or not a case is in the set. We define these thresholds at twelve competitors and two competitors (duopoly), respectively. No monopoly occurred within the data. The cross-over point of 4.5 competitors might seem strange. There is no situation where there are four and a half competitors in a market. With regard to the analysis with fuzzy algebra and membership scores, the value of 4.5 was chosen because it does not determine a market as neither a member nor non-member of the set 'structurally competitive markets', i.e. the membership of 0.5 . Regarding the analysis the important information remains true. Whether a market is constituted of four or five firms, the respective membership score will indicate such a situation. A market constituted of four or less competitors will be assigned a membership of less than 0.5 and thus indicating a structurally low competitive market. This is in line with the research on financial commitment in the U.S. The anchor points for the transformation of the competition intensity values $(\mathrm{CI})$ are defined at $0.95,0.80$, and 0.60 . The value 0.95 indicates that two competitors are in highly intensive competition if divided by only five per cent in market share. If the difference is more than $40 \%$, e.g. the leading newspaper with a market share of $50 \%$ and the competitor under examination with $10 \%$ or less of market share, the competitor is fully out of the set of high competition intensity. It is argued that the reaction of one competitor to another competitor's action is faster and more intense if they are close in terms of market share (Lacy, 1992). Fuzzy membership scores for the set high past level of profits are assigned directly because the measurement of the variable is based on ordinal data. Profit margins above 5\% are said to be in the set of high level of past profits.

The logic of the calibration of the shares of ad expenditures into the press sector into the set press system is based on simple relations to shares of the other media types. A share of over a half indicated by the anchor of $55 \%$ shows full membership in the set 'press system'. 
In contrast, a share of under a fifth (20\%) indicates full non-membership in the same set. The benchmark of one-third indicates the cross-over point.

Calibration of the average growth of the ad expenditures in press over the past three years follows the threshold of $0 \%$ for full membership and $-0.15 \%$ for full non-membership, respectively. A case is, thus, fully in the set if the recession did not hit the respective market at full strength, i.e. the development of advertising expenditures of the past years is recovering.

The calibrations of the outcomes follow the same principles (table 2). The memberships in the set of high editorial budget are calibrated along the anchors of 250.000, 100.000, and 20.000 Swiss francs per thousand copies and year. The anchors are chosen on the grounds of simple arithmetic plausibility and the distribution of cases. A daily newspaper produces between 260 and 360 editions a year depending on whether it is a work week paper or a full week paper, including Sunday's edition. As such, a minimum of one franc per copy and day is said to be a high budget paper. A paper that reveals less than 10 cents per copy is said to be completely out of the set. The same procedure, relying on plausibility and case distribution, is applied to the set high share of full-time journalists in newsrooms. The crossover point is defined at 0.5 . A value of 1.7 indicates full membership in the set of high share of full-time journalists in newsrooms. Table 2 summarizes the fuzzy membership score for each case after the calibration process.

\section{$<<<$ Place table 2 about here $>>>>$}

\section{Results}

Similarly to regression analysis, QCA is separately performed for every single outcome. The goal of QCA is to identify the different combinations of causally relevant conditions leading to an outcome. The test of necessary condition antecedes the test of sufficiency. With regard to the quality criteria a necessary condition should meet a 
consistency value of at least 0.9 (Schneider \& Wagemann, 2010) and coverage should be high as well. A low value might be indicative for trivialness (Goertz, 2006). In the whole analysis there is only one necessary condition: Almost every time a newspaper has a high editorial budget it is a member in the set press system (PS־BUDG, consistency: 0.95, coverage: 0.76).

In the following we will focus on the tests of sufficiency according the two hypotheses. In line with $\mathrm{H} 1$ the conditions PS, AD, NR and CI are tested against the outcomes. In order to facilitate subsequent analyses we will firstly introduce how a fuzzy set solution is read and compare it secondly to regression analysis for illustrative purposes only. Therefor we test the model JOURN=f(PS,AD,NR,CI) (see table 3). According to the financial commitment hypotheses we set 'CI' and ' $\mathrm{nr}$ ' to 'present' in order to reach the intermediate solutions in fsQCA (counterfactual analysis). The solution term consists of only one path that leads to the outcome (table 3). The solution for sufficiency is read as follows: "If a newspaper has a high share of full-time journalists in the newsroom the same newspaper acts almost always in a market with many competitors within a media system that is dominated by ad expenditures into the press." The limitation 'almost always' refers to the fact that the solution is not perfectly consistent (0.86). Nevertheless, the combination of PS and NR can be seen as a sufficient condition for newspapers with high shares of full-time journalists (consistency values for sufficient condition $>0.8$, Ragin, 2008a, p. 45). ${ }^{3}$ In addition, the coverage of the term indicates that it is empirically relevant (0.59), too. Again the solution does not 'cover' the outcome perfectly because some Swiss national dailies are not members in the combination of conditions NR*PS. Again we would like to stress that fsQCA identifies sufficient conditions for an outcome. Cases with membership $>0.5$ in the outcome and the counterfactuals are the bases of the analysis. Even cases with membership $<0.5$ in the (combination of) conditions, i.e. the Swiss dailies, are in line with the solution if these cases are consistent with the set theoretic logic for sufficiency $(\mathrm{X} \leq \mathrm{Y})$. Hence, the inspection of both

\footnotetext{
${ }^{3}$ In a X-Y-Plot almost all cases would lie above the main diagonal indicating $\mathrm{X} \leq \mathrm{Y}$.
} 
quality criteria as well as the qualitative investigation of the cases is crucial. We may conclude that being a newspaper in a so called press system where the resource potential is high is obviously a key condition for high financial commitment within the markets analysed. It explains why there are only newspapers from Germany, Denmark or Switzerland in the column 'titles' (table 3). The condition 'structurally competitive markets' (NR) is a key element, too. It seems that in Europe - at least for the cases under examination - a high number of competitors in a market is one important condition for high financial commitment. But, neither PS nor NR alone is a sufficient condition for the outcomes.

$\ll<<$ place table 3 about here $\gg>>$

If we run an OLS regression analysis for the same model without interaction effects we get the following solution: Standardized Betas for PS $0.791(\mathrm{p}<0.001)$, NR 0.554 and CI 0.402 (both $\mathrm{p}<0.05$ ); adjusted $\mathrm{R}^{2}=0.57$. Thus, regression analyses leads to the same solution apart from the variable CI which has a significant effect on high shares of journalists in newsrooms, too. The difference to the QCA solution is of a mere technical concern. PS*NR*CI is a subset of PS*NR (subsethood is indicated by $\leq$ ). ${ }^{4}$ If we set the cut-off values in the first row of table 3 at 0.90 and two cases, we find the solution path PS*NR*CI. Thus, both methods formally reveal the same causal statement. It may be seen as strong support for the solution identified if two different causal analyses reveal the same pattern (Katz, Vom Hau, \& Mahoney, 2005). In addition, the difference in the strength of the coefficients reveals the same pattern as in QCA. PS and NR show the biggest effects and account for the highest share of variance explained. Nevertheless, from the results of the regression analysis we cannot conclude that all three variables combined lead to high financial commitment without conducting interaction effects. Such an analysis would certainly be out of all proportion to the

\footnotetext{
${ }^{4}$ Cases that are members in the intersection of two sets are also members in the original sets.
} 
sample size in the present study. In addition, interpretation of complex three or more times interaction effects is very obscure, whereas the results from QCA do reveal a single and interpretable statement: Neither PS nor NR nor CI alone is a sufficient condition for a high share of full-time journalists in newsrooms. Only their combination is. It is one aspect of QCA that it allows for conjunctural causation (Rihoux, 2006, p. 682). For the outcome high editorial budget (BUDG) the same solution is found (table 3).

Another aspect of QCA with regard to causal statements is equifinality. It refers to a situation where there are two or more separate paths each leading to the outcome. In the following the model referring to $\mathrm{H} 2$ is tested. Given the sample size in this study, we exclude the condition $\mathrm{AD}$ which already lacks explanatory power in the first step (H1) while introducing the condition PROFIT $(\mathrm{H} 2){ }^{5}$

Equifinality is given because two different combinations of conditions are each leading to the outcome (lower half of table 3). Again the conditions press system and structurally competitive markets are key elements and lead either in a situation of high competition intensity or in combination with high profits in the past year to a high share of full-time journalists in newsrooms. The path PS*NR*PROFIT has a unique coverage of only 0.04. Its empirical relevance is, thus, not quite as high as the one of PS*NR*CI. The latter path exclusively covers a good part of the outcome JOURN (unique coverage 0.21 ). The overall solution PS*NR*(CI + PROFIT) is highly consistent $(0.91)$ with the notion $\mathrm{X} \leq \mathrm{Y}$. Equifinality is given for the outcome BUDG, too, but the two combinations of conditions differ from the ones just described for the outcome JOURN. A high editorial budget in a newspaper is almost always given if the same paper stems from a press system where there is high competition in a market in terms of number of competitors or where there is low intensity of competition and the newspaper examined made no or marginal profits the past

\footnotetext{
${ }^{5}$ Although QCA is suitable for small $\mathrm{n}$ studies, its functionality depends on an appropriate relation of the number of cases and the number of conditions tested, too (Schneider \& Wagemann, 2010).
} 
year. Again there is a difference in explanatory power between the two paths. The path NR*PS reveals a unique coverage of 0.32 whereas the second solution term PS*profit*ci accounts only for 0.07 of unique coverage. Hence, newspapers with membership greater than 0.5 in the second term and the outcome are Le Temps and FAZ. The title Die Welt is a true violation meaning that it is a member in the condition but does not show the outcome under investigation. Was it not for Die Welt the consistency score of the term would increase from 0.80 to 0.86 .

The solution presented so far only explain German, Danish and to some extent Swiss cases because of the ubiquitous condition press system. Neither Swiss national dailies nor newspapers from Italy or France are explained (table 3, column 'titles'). This does not mean that the solutions presented so far are of minor relevance. The reported coverage scores show the empirical importance regarding the set relations examined. But it is another crucial aspect of QCA that its configurational setting helps researchers to make sense of their cases (Ragin 2006a, p. 309). For example, in the case of Swiss-German dailies it is due to the narrow market (nr). But even the condition high intensity of competition has no explanatory power. In order to assess the assumption of the financial commitment across all contexts in this study we exclusively tested the conditions CI, NR and PROFIT against both outcomes. The separate fuzzy set analysis for the outcome JOURN reveals the solution $\mathrm{NR}^{*}(\mathrm{CI}+$ profit). Twelve newspapers out of 18 from every country examined are members in these combinations of conditions. Coverage, thus, is high with 0.75 and the solution is ample consistent with fuzzy subsethood (0.82). Thus, for every country except Switzerland (the national daily newspaper market is a narrow oligopoly) it holds true that structurally competitive markets (NR) in combination with either high competition intensity or low past profits lead to high shares of full-time journalists in newsrooms. The same analysis for the outcome BUDG could not be specified on the bases of adequate cut-off criteria in the respective truth table. There are too many contradictory cases within the configurations which would render the solution terms 
inconsistent and the analysis unstable. Because these findings are contradictory to the traditional financial commitment assumption they will scrutinize the relationship of profit and competition more closely in the discussion.

In conclusion and before turning to the discussion and interpretation of the results we make a methodological remark. The set theoretic bases of QCA and as such the asymmetrical principle of causality would require the test of both the outcome and its negation. The analysis of the negated outcomes is not a mere methodological concern but may reveal the conditions that determine low financial commitment. In line with the hypotheses and the overall goal of the paper we do not explicate these analyses any further than the theoretical argument of a possible non-linear relationship due to very high competition. We do not find evidence for this assumption. The fuzzy set analyses of the negated outcome identify that the absence of a high share of ad expenditures into the press (ps) is a key element for the negated outcomes similar to its presence for the outcome. The solution terms are depicted in table 4. The inspection of the cases reveals that most are free dailies in non-press systems. Albeit all cases with low financial commitment within the context non-press system (France and Italy) could be explained, the problem with the presented solution lies within the applicability across all contexts, i.e. newspapers with low budgets and small staff in the countries $\mathrm{CH}, \mathrm{DK}$ and $\mathrm{DE}$. But even in these contexts none of the cases are explained by high competition $(\mathrm{NR} * \mathrm{CI})$ which would be indicative for the hypercompetition hypothesis.

$\ll<<$ place table 4 about here $\gg>>>$

\section{Discussion}

Although QCA is fruitfully applied within sociology and political science tests of hypothesis are rare or merely descriptive in nature, i.e. where and whether the assumed relationship is found in the empirical data as well. We try to evaluate theory by comparing the 
theoretical solutions with the empirical solutions. As a tentative test criterion consistency scores of both solutions are compared (Schneider \& Wagemann, in press). In essence, H1 and $\mathrm{H} 2$ can be formally written as follows:

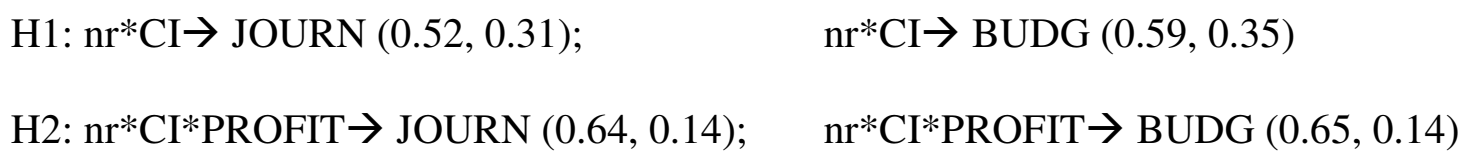

None of the presented empirical solutions are formally congruent with these terms. In addition, the consistency and coverage scores in parenthesis indicate that the traditional assumption of financial commitment does not fit the empirical data examined in this paper. All consistency scores are way below the acceptance level of 0.8. Of course, this does not mean that high competition (intensity) has no effect on financial commitment. We find that a high number of competitors in combination with high competition intensity are a sufficient condition for a high share of full-time journalists across all contexts. Sole exceptions are Swiss national dailies. In contrast to research on financial commitment in the U.S. the condition 'number of competitors' is crucial in Europe. Thus, it seems that financial commitment into news is not strictly bound to non-normal profits found in narrow oligopolies - at least in Europe - as Lacy (1992, p. 14) assumed. Financial commitment into news production seems to apply to a wider range of profit levels. In essence, the whole relationship of profit and financial commitment is more complex. Indeed, the level of financial commitment might be a function of past profits but it is also dependent on the management strategy and advance planning. Thus, longitudinal studies are required and the explanatory power of low past profits for high financial commitment might still be due to the special context of the study taking place during the years of economic downturn. Our study solely shows that the level of past profit is of minor importance regarding the assumption of the financial commitment approach and, especially, if compared to the overall availability of resources measured as the share of ad expenditures into the press sector. This context factor 'press system' is a ubiquitous element of all sufficient conditions and at the same time a 
necessary condition for high editorial budgets. It was introduced in order to 'control' for the overall resource availability which is an important determinant of financial commitment. In sum, the potential for and the level of financial commitment in a market depends on the number of competitors and, at least to some extent, on the competition intensity in terms of proximity of market shares. In addition, the financial commitment of the investigated newspapers in a market is not only a function of competition but also of the amount of resources available to the media firms.

The test of the outcomes of low financial commitment in the study at hand reveals that the data does not fit the notion of hypercompetition reducing resource allocation on an organizational level as argued by Hollifield and others. In contrast, high competition in terms of number of newspapers and intensity $(\mathrm{NR} * \mathrm{CI})$ is a sufficient condition for high financial commitment measured as the share of full-time journalists in a newsroom. With regard to the limitations of the study a critical remark is necessary. The solutions for low financial commitment cover almost exclusively free daily newspapers. Low organizational resources are part of their business model (Bakker, 2002). Thus, it remains for speculation whether few competitors in a non-press system are a sufficient condition for low financial commitment or whether it is simply characteristic of the cases examined.

In general, the results presented in this study are limited to the cases examined. We were not able to fully cover every market with our data. However, we do not think that the patterns found would change. The results are, at least, partially consistent across different contexts. Still, it remains for speculations. Even counterfactual analysis as a way to deal with remainders in QCA cannot reveal general patterns that lie beyond the sample of this study. Thus, the results and corresponding interpretations are tentative even though the cases were purposefully selected in order to address the requirements of the financial commitment model.

Nevertheless, the study is a first test of the financial commitment model in Europe and, as such, within different contexts than the traditional line of research. The context- 
sensitiveness of theoretical assumptions of the middle range is a main concern of comparative research. This study reveals that even within Europe there are differences across contexts notwithstanding the overall pattern that was found. But it is not only the context-sensitiveness that implies complexity. After all, there are many discussions about media markets being 'fuzzy' and two sided (Anderson \& Gabszewicz, 2006; Kaiser \& Wright, 2006; Lacy, 2004, Lacy, 1993). In addition, market forces may be entangled by intermedia competition (Dimmick, Patterson, \& Albarran, 1992; Lacy, 1988) and a convergent environment (Wirth, 2006). Hence, the relationship of structure, conduct, and performance is complex and multidimensional. Future research should set out to unravel such complexities, continuing while contemporaneously broadening existing research and theory. This study is a first step in this direction. In particular, it is a first attempt to introduce fsQCA to the field of media economics. Its ability to unravel causal conjunctures is as fruitful to the field as its qualification for studies with small to medium-sized samples. This is of utmost importance when dealing with social phenomena that are naturally limited in numbers (Rihoux, 2006).

\section{References}

Anderson, S. P., \& Gabszewicz, J. J. (2006). The media and advertising: A tale of two-sided markets. In V. A. Ginsburgh \& C. D. Throsby (Eds.), Handbooks in economics: Vol. 25. Handbook of the economics of art and culture (pp. 567-614). Amsterdam \& Oxford, UK: North-Holland.

Bakker, P. (2002). Free daily newspapers - business models and strategies. International Journal on Media Management, 4(3), 180-187.

Becker, L. B., Hollifield, C. A., Jacobsson, A., Jacobsson, E.-M., \& Vlad, T. (2009). Is more always better?: Examining the adverse effects of competition on media performance. Journalism Studies, 10(3), 368-385.

Berg-Schlosser, D., \& Cronqvist, L. (2005). Macro-quantitative vs. macro-qualitative methods in the Social Sciences: An example from empirical democratic theory employing new software. Historical Social Research, 30(4), 154-175.

Busterna, J. C. (1980). Ownership, CATV and expenditures for local television news. Journalism Quarterly, 57(Summer), 287-291.

Chen, R., Thorson, E., \& Lacy, S. (2005). The impact of newsroom investments on newspaper revenues and profits: Small and medium newspapers, 1998-2002. Journalism \& Mass Communication Quarterly, 82(3), 516-532. 
Cho, H. (2000). The impact of newspaper competition and ownership on resource allocation : a study in japan: Michigan State University, Dept. of Mass Media, Ph.D. dissertation.

Cho, S., Thorson, E., \& Lacy, S. (2004). Increased circulation follows investments in newsroom. Newspaper Research Journal, 25(4), 26-39.

Cooper, B., \& Glaesser, J. (2011). Paradoxes and pitfalls in using fuzzy set QCA: Illustrations from a critical review of a study of educational inequality. Sociological Research Online, 16(3), 1-8. Retrieved from http://www.socresonline.org.uk/16/3/8.html

Dimmick, J. W., Patterson, S. J., \& Albarran, A. B. (1992). Competition between the cable and broadcast industries: A niche analysis. Journal of Media Economics, 5(1), 13-30.

Goertz, G. (2003). Necessary conditions: Theory, methodology and applications. Lanham, Md: Rowman \& Littlefield.

Goertz, G. (2006). Assessing the trivialness, relevance, and relative importance of necessary or sufficient conditions in social science. Studies in Comparative International Development, 41(2), 88-109.

Goertz, G., \& Mahoney, J. (2005). Two-level theories and fuzzy-set analysis. Sociological Methods \& Research, 33(4), 497-538.

Hallin, D. C., \& Mancini, P. (2004). Comparing media systems: Three models of media and politics. Communication, society and politics. Cambridge: Cambridge University Press.

Hollifield, C. A. (2006). News media performance in hypercompetitive markets: An extended model of effects. International Journal on Media Management, 8(2), 60-69.

Humphreys, P. (2012). A political scientist's contribution to the comparative study of media systems in Europe: A response to Hallin and Mancini. In N. Just \& M. Puppis (Eds.), Trends in communication policy research (pp. 157-176). Bristol: Intellect.

Kaiser, U., \& Wright, J. (2006). Price structure in two-sided markets: Evidence from the magazine industry. International Journal of Industrial Organization, 24(1), 1-28.

Katz, A., Vom Hau, M., \& Mahoney, J. (2005). Explaining the great reversal in Spanish America: Fuzzy-set analysis versus regression analysis. Sociological Methods \& Research, 33(4), 539-573.

Kohn, M. L. (1987). Cross-national research as an analytic strategy. American Sociological Review, 52(6), 713-731.

Lacy, S. (1988). The impact of intercity competition on daily newspaper content. Journalism Quarterly, 65(2), 399-406.

Lacy, S. (1992). The financial commitment approach to news media competition. Journal of Media Economics, 5(2), 5-21.

Lacy, S. (1993). Understanding and serving readers: The problem of fuzzy market structure. Newspaper Research Journal, 14(2), 55-67.

Lacy, S. (2004). Fuzzy market structure and differentiation: One size does not fit all. In R. G. Picard (Ed.), JIBS Research report Series. Strategic responses to media market changes (pp. 83-97). Jönköping: Jönköping International Business School.

Lacy, S., \& Blanchard, A. (2003). The impact of public ownership, profits, and competition on number of newsroom employees and starting salaries in mid-sized daily newspapers. Journalism \& Mass Communication Quarterly, 80(4), 949-968.

Lacy, S., \& Riffe, D. (1994). The impact of competition and group ownership on radio news. Journalism \& Mass Communication Quarterly, 71(3), 583-593.

Lacy, S., \& Simon, T. F. (1993). The economics and regulation of United States newspapers. Norwood, NJ: Albex. 
Lacy, S., Atwater, T., \& Qin, X. (1989). Competition and the allocation of resources for local television news. Journal of Media Economics, 2(1), 3-14.

Lacy, S., Fico, F., \& Simon, T. (1989). Relationships among economic, newsroom, and content variables: A path model. Journal of Media Economics, 2(2), 51-66.

Litman, B. R., \& Bridges, J. (1986). An economic analysis of daily newspaper performance. Newspaper Research Journal, 7(3), 9-26.

Livingstone, S. M. (2003). On the challenges of cross-national comparative media research. European Journal of Communication, 18(4), 477-500.

Luoma, P. (2006). Social sustainability of community structures:: A systematic comparative analysis within the Oulu Region in Northern Finland. In B. Rihoux \& H. Grimm (Eds.), Innovative Comparative Methods for Policy Analysis. Beyond the quantitative-qualitative divide (pp. 237-262). New York N.Y: Springer.

McNulty, P. J. (1968). Economic theory and the meaning of competition. The Quarterly Journal of Economics, 82(4), 639-656.

Picard, R. G. (2002). The economics and financing of media companies. New York: Fordham University Press.

Picard, R. G., \& Russi, L. (2012). Comparing media markets. In F. Esser \& T. Hanitzsch (Eds.), ICA handbook series. The handbook of comparative communication research (pp. 234-248). London: Routledge.

Powers, A. (1993). Competition, conduct, and ratings in local television news: Applying the industrial organization model. Journal of Media Economics, 6(2), 37-44.

Ragin, C. C. (1987). The comparative method: Moving beyond qualitative and quantitative strategies. Berkeley, CA: University of California Press.

Ragin, C. C. (2000). Fuzzy-set social science. Chicago: University of Chicago Press.

Ragin, C. C. (2005). From fuzzy sets to crisp truth tables (Working Paper No. WP2004-28). Retrieved from http://www.compasss.org/files/WPfiles/Raginfztt_April05.pdf

Ragin, C. C. (2006a). Set relations in social research: Evaluating their consistency and coverage. Political Analysis, 14(3), 291-310. doi:10.1093/pan/mpj019

Ragin, C. C. (2006b). The limitations of net-effects thinking. In B. Rihoux \& H. Grimm (Eds.), Innovative Comparative Methods for Policy Analysis. Beyond the quantitativequalitative divide (pp. 13-41). New York N.Y: Springer.

Ragin, C. C. (2007). Fuzzy sets: Calibration versus measurement (Compasss Working Paper No. WP2007-44). Retrieved from http://www.compasss.org/files/WPfiles/Ragin2007.pdf

Ragin, C. C. (2008a). Redesigning social inquiry: Fuzzy sets and beyond. Chicago: University of Chicago Press.

Ragin, C. C. (2008b). User's guide to fuzzy set / Qualitative Comparative Analysis 2.0. Tucson, AZ. Retrieved from http://www.u.arizona.edu/ cragin/fsQCA/download/fsQCAManual.pdf

Rihoux, B. (2006). Qualitative comparative analysis (QCA) and related systematic comparative methods: Recent advances and remaining challenges for social science research. International Sociology, 21(5), 679-706.

Sánchez-Tabernero, A., \& Carvajal, M. (2002). Media concentration in the European market: New trends and challenges. Pamplona: Servicio de Publicaciones de la Universidad de Navarra.

Schneider, C. Q., \& Wagemann, C. (2010). Standards of good practice in Qualitative Comparative Analysis (QCA) and Fuzzy-Sets. Comparative Sociology, 9(3), 397-418. 
Schneider, C. Q., \& Wagemann, C. (in press). Set-Theoretic Methods: A user's guide for Qualitative Comparative Analysis and Fuzzy Sets in social science. Cambridge: Cambridge University Press.

St. Cyr, C., Lacy, S., \& Guzman-Ortega, S. (2005). Circulation increase follows investment in newsrooms. Newspaper Research Journal, 26(4), 50-60.

Tirole, J. (1988). The theory of industrial organization. Cambridge, MA: MIT Press.

van Cuilenburg, J. (1999). On competition, access and diversity in media, old and new: Some remarks for communications policy in the information age. new media \& society, 1(2), 183-207.

van der Wurff, R., \& van Cuilenburg, J. (2001). Impact of moderate and ruinous competition on diversity: The Dutch television market. Journal of Media Economics, 14(4), 213-229.

Wirth, M. O. (2006). Issues in media convergence. In A. B. Albarran, S. M. Chan-Olmsted, \& M. O. Wirth (Eds.), Handbook of media management and economics (pp. 445-462). Mahwah, NJ: Lawrence Erlbaum Associates. 